\title{
Study of Premature Infant during Early Period of Life
}

\author{
M A A Mamun ${ }^{1}$, M M Hoque ${ }^{2}$, M A K A Chowdhury ${ }^{3}$ \\ M M Hossain ${ }^{4}$, M Shirin ${ }^{5}$, L Y Ye
}

${ }^{1}$ Dr. Mohammad Abdullah AI Mamun Intensivist

Dept. of Paediatric Cardiology

Dhaka Shishu (Children) Hospital

${ }^{2}$ Prof. Md. Mahbubul Hoque

Professor

Dept. of Neonatology

3 Prof. M A K Azad Chowdhury

Professor and Head

Dept. of Neonatology

${ }^{4}$ Prof. M Monir Hossain

Professor

Dept. of Critical Care in Paediatric

${ }^{5}$ Dr. Mahfuza Shirin

Associate Professor

Dept. of Neonatology

${ }^{6}$ Dr. Lee Le Ye

Consultant, Dept. of Neonatology

National University Hospital

Singapore

\section{$2,3,4,5$}

Bangladesh Institute of Child Health \& Dhaka Shishu (Children) Hospital

\section{Correspondence}

Dr. Mohammad Abdullah AI Mamun Intensivist

Dept. of Paediatric Cardiology

Dhaka Shishu (Children) Hospital

E-mail: mamun_dsh@yahoo.com
Abstract :

Background : There is suboptimal growth observed among the very low birth weight (VLBW) infants during postnatal period.

Objectives : This study was conducted to evaluate the anthropometric parameters among preterm VLBW infants during early period of life.

Methods : This was a retrospective study of preterm VLBW infants admitted to Dhaka Shishu (Children) Hospital during the period of July 2011 to June 2013. Body weight, length and occipitofrontal circumference (OFC) at birth and at 4 weeks was recorded from neonatal data base. Z-scores for each anthropometric parameter were computed using Fenton's growth chart of preterm infants. Statistical analysis was done using SPSS version 21.0 .

Results : Total 88 preterm VLBW infants were included in the study and among them male were $61.4 \%$ and female were $38.6 \%$ with a male female ratio $1.59: 1$. Mean weight, length and OFC at birth was $1186 \pm 277.45 \mathrm{gm}, 38.23 \pm 2.89 \mathrm{~cm}$ and $27.46 \pm 2.20 \mathrm{~cm}$ respectively and at 4 weeks $1460.81 \pm 295.73$ $\mathrm{gm}, 41.23 \pm 2.87 \mathrm{~cm}$ and $29.91 \pm 2.19 \mathrm{~cm}$ respectively. At birth small for gestational age (SGA) was found in $44.3 \%$ but at 4 weeks majority $(77.3 \%)$ failed to achieve appropriate weight. $Z$ score of weight, length and OFC at birth was $-1.19,-0.58$ and - 0.24 respectively and at 4 weeks-2.01, -1.17 and -0.75 respectively. There was a significant decline in all three anthropometric parameters from birth to 4 weeks of life $(\mathrm{p}<0.05)$

Conclusion : There was decrease in all anthropometric parameters among preterm VLBW neonate at 4 weeks of life. Despite significant decrease in somatic growth they maintained a near normal head growth.

Key wards: Anthropometric parameters, preterm VLBW infant.

\section{Introduction}

The survival rate of premature infants especially VLBW infants has improved steadily over the last decades but raises a number of management dilemmas regarding post-natal growth failure. To ensure early postnatal growth for preterm infants adequate nutrition is essential. Intrauterine growth is supported by continuous supply of nutrients from mother to the fetus throughout pregnancy therefore preterm birth causes disruption in delivery of nutrients to the fetus. VLBW neonates, remained growth retarded even at corrected age (CA) of one year. ${ }^{1}$ They also had a significant drop in all Zscores by discharge at 40 weeks post menstrual age (PMA), and even at 12 months of CA. ${ }^{2}$

Premature infants are deprived of normal intrauterine nutrient supply and growth during last trimester. Inadequate nutrient intakes have been implicated as the cause of the occurrence of postnatal growth failure in premature infants. Various morbidities also contribute to the growth failure and delays in regaining birth weight. In order to allow growth rate similar to that seen in utero, or avoid extra-uterine growth retardation there should be no interruption in delivery of nutrients from time of birth onwards. ${ }^{3}$

Extra-uterine growth retardation is associated with adverse outcomes including chronic lung disease, increased risk to infection and abnormal neurodevelopmental outcome. Disturbances of intrauterine and postnatal growth during critical periods of human development may have longterm implications for health. Several studies have reported high incidence of growth failure and poor neurological outcome during infancy and childhood. ${ }^{4-6}$ Khan et al in Bangladesh found that two thirds of preterm infant developed neurodevelopmental impairments. ${ }^{7}$

The aim of this study was to evaluate the anthropometric parameters among preterm VLBW infants during early period of life.

\section{Materials and methods}

Total 88 premature infant weighing $<1500 \mathrm{gm}$, 
admitted to neonatal ward from July 2011 to June 2013 were enrolled. Data were collected retrospectively from neonatal data base regarding weight, length and OFC at birth and at 4 weeks of life.

Infants who died, had gross congenital malformation and discharged or transfer out before 4 weeks of life were excluded from the study. Gestational age was recorded as per date of last menstrual period. Weight was taken on admission, on electronic weighing scale, with baby being unclothed. Length and OFC were taken using standard techniques and repeated at 4 weeks of life.

All premature infants were started on enteral feeds as soon as possible alone with IV fluid. Enteral feeds were increased gradually to a volume of $150-180 \mathrm{ml} / \mathrm{kg} /$ day. Expressed breast milk was preferred; where not available, premature formula was used. Z-scores for each anthropometric parameter were computed using Fenton's reference. ${ }^{8-9}$ Infants below $10^{\text {th }}$ centile were categorized as small for SGA. Statistical analysis was done using SPSS version 21.0. Comparisons were made using independent $t$ test.

\section{Results}

Among the 88 premature infants mean gestational age was $30.72 \pm 2.30$ weeks and among them $44.3 \%$ was found SGA at birth. Mean birth weight was $1186 \pm 277.45 \mathrm{gm}$. Male are $61.4 \%$ and female were $38.6 \%$ with a male female ratio 1.59:1 (Table-I).

Table-I : Clinical and demographic features of study population $(n=88)$

$\begin{array}{lcc} & \text { Variable } & \text { Number (\%) } \\ \text { Gestational age } & \text { Mean, weeks }( \pm \text { SD) } & 30.72( \pm 2.30) \\ \text { Category of infants } & \text { SGA } & 39(44.3) \\ & \text { AGA } & 49(55.7) \\ \text { Birth weight } & \text { Mean, gm }( \pm \text { SD) } & 1186( \pm 277.45) \\ & 1000-1500 \mathrm{gm} & 58(65.9) \\ \text { Sex } & <1000 \mathrm{gm} & 30(34.1) \\ & \text { Male } & 54(61.4) \\ & \text { Fmale } & 34(38.6)\end{array}$

Breast milk was used as enteral feed in majority cases (63.64\%). Preterm formula (14.77\%) was used when breast milk was not available. Mean age of starting enteral feed was3.4 \pm 2.1 days and mean age of establishment of full enteral feeding was $14.8 \pm 4.6$ days (Table-II).

\section{Table-II Distribution of type of enteral feeding $(n=88)$}

Type of feed

Breast milk

Formula milk

Mixed

Age at first enteral feeding (days),

Age at full enteral feeding (days)

\section{Number $(\%)$}

$56(63.64 \%)$

$13(14.77 \%)$

$19(21.59 \%)$

$3.4 \pm 2.1($ Mean $\pm S D)$

$14.8 \pm 4.6($ Mean \pm SD $)$
Most common morbidities were feed intolerance (37.50\%), sepsis (31.82\%), anaemia of prematurity (17.05\%), Hypoglycaemia (18.18\%), perinatal asphyxia (15.90\%), PDA $(9.90 \%)$ and RDS $(9.90 \%)$ [Table-III].

$\begin{array}{lcc}\text { Table-III Morbidities among the premature infant (Multiple responses) } & \text { Number } & \% \\ \text { Morbidities } & 28 & 31.82 \\ \text { Sepsis } & 14 & 15.90 \\ \text { Perinatal Asphyxia } & 15 & 17.05 \\ \text { Anaemia of prematurity } & 8 & 9.90 \\ \text { PDA } & 16 & 18.18 \\ \text { Hypoglycaemia } & 3 & 3.41 \\ \text { NEC } & 5 & 5.68 \\ \text { IVH } & 8 & 9.90 \\ \text { RDS } & 3 & 3.41 \\ \text { ROP } & 2 & 2.27 \\ \text { Pulmonary haemorrhage } & 33 & 37.50 \\ \text { Feed intolerance } & \end{array}$

Mean weight, length and OFC at birth was $1186 \pm 277.45 \mathrm{gm}$, $38.23 \pm 2.89 \mathrm{~cm}$ and $27.46 \pm 2.20 \mathrm{~cm}$ respectively and at 4 weeks $1460.81 \pm 295.73 \mathrm{gm}, 41.23 \pm 2.87 \mathrm{~cm}$ and $29.91 \pm 2.19 \mathrm{~cm}$ respectively and compared with $50^{\text {th }}$ centile of Fenton's growth chart at birth and at 4 weeks and found far below $50^{\text {th }}$ centile.(Fig. 1)

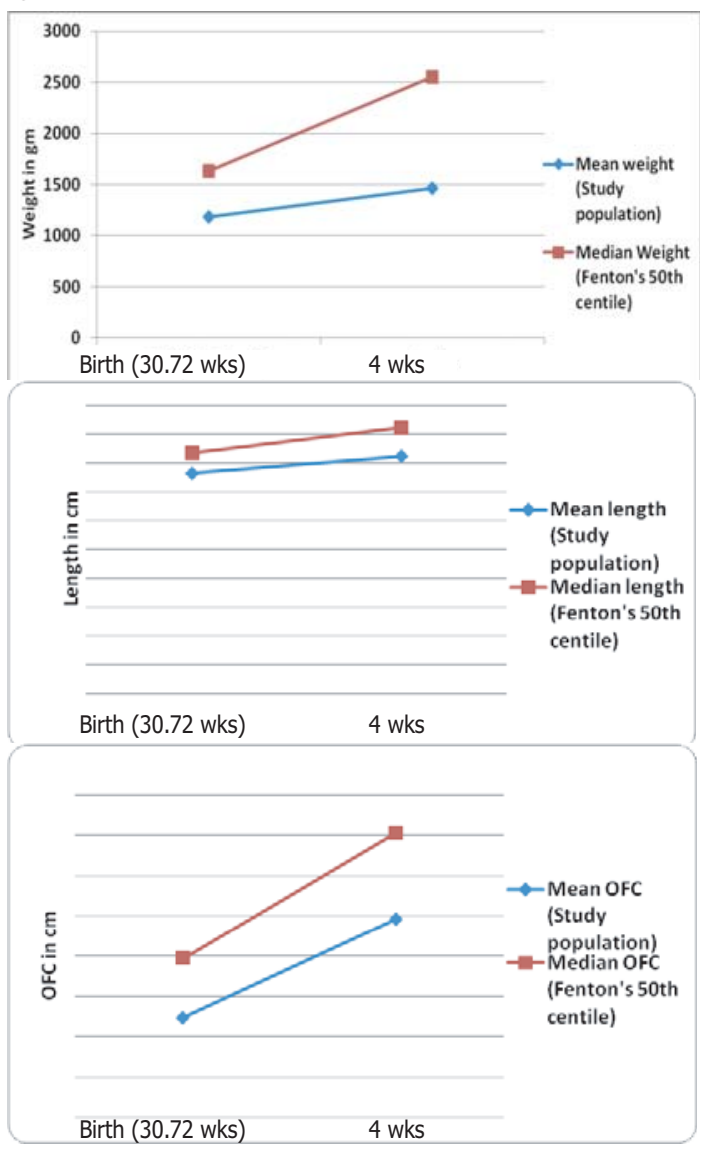

Fig.-1 Comparison of weight, length and OFC with $50^{\text {th }}$ centile of Fenton's growth chart 
Among the premature infants there was a significant decline in all three anthropometric parameters from birth to 4 weeks of age $(p<0.05)$. Weight $Z$ score declines to -2.01 but length and OFC was maintained above -1.28SD (Fig.-2).

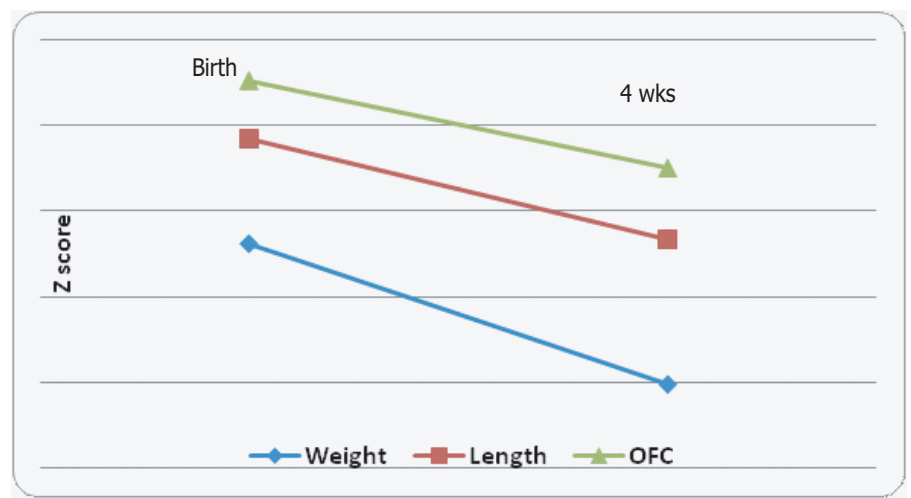

Fig.-2 Growth pattern of VLBW infant at birth and 4 weeks

Among the premature infants $44.3 \%$ were SGA at birth. But at 4 weeks $77.3 \%$ were failed to achieve appropriate weight as Fenton's growth chart (Fig.-3).

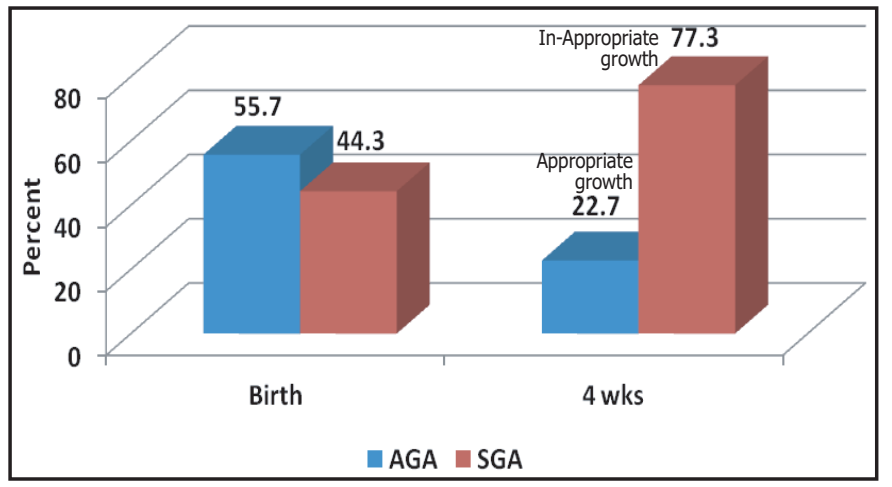

Fig.-3 Distribution of SGA at birth and growth of neonate at 4 weeks

\section{Discussion}

In this study among the preterm VLBW neonates $44.3 \%$ were found SGA at birth. Data from 138 low and middle income countries in 2010 collected by Child Health Epidemiology Reference Group showed that $41 \%$ of preterm were SGA ${ }^{10}$, Modi et $\mathrm{al}^{2}$ found $46 \%$ in India and Mackay et al ${ }^{11}$ found $48.9 \%$ in South Africa and Westerberg et al ${ }^{12}$ found $32.2 \%$ in Norway. The variation may be due to difference in socioeconomic factors, ethnicity and perinatal morbidities. At 4 weeks of life $77.3 \%$ preterm infants were failed to achieve appropriate weight in this study. That means majority of premature infants have growth failure at 4 weeks of life. Studies have focused on infants born SGA seem to be particularly prone to later growth restriction. ${ }^{13,14}$

Our study showed feed intolerance (33\%) was common morbidity and other morbidities were Neonatal sepsis, Neonatal hypoglycemia, Anemia of prematurity and Perinatal asphyxia $28 \%, 16 \%, 15 \%$ and $14 \%$ respectively. Starting of enteral feeding was 3.4 \pm 2.1 (Mean \pm SD) days and enter into full enteral feed was $14.8 \pm 4.6$ (Mean \pm SD)days. It may not always be possible to start feeds soon after birth and, even when such a practice is possible, oral feeds often do not provide adequate nutrition until full feeds are given, which might take time. In this study starting of feed was earlier but full establishment was late which was considered as reason for poor catch up growth at 4 week of age.

This was consistent with the study done by Ehrenkranz et al ${ }^{15}$ found most VLBW infants did not achieve catch-up growth during the neonatal intensive care unit hospitalization compared with median birth weight at same postmenstrual age. Rate of weight gain in their study was affected by morbidities, age of starting enteral feeding and age of establishing full enteral feeding.

In this study premature infants at birth had lower $Z$ score for weight, length and OFC compared to median value of Fenton's chart. 8,9 There was a significant decline in all three anthropometric parameters from birth to 4 weeks of life $(p<0.05)$. Weight in $Z$ score declines to -2.01 but length and OFC maintained above $-1.28 \mathrm{SD}$ indicated that weight was affected more but length and head growth was maintained near normal.

Most of the babies (63.64\%) in this study were breast feed. Cockerill et $\mathrm{al}^{16}$ showed that despite slow somatic growth extreme preterm infant show accelerated postnatal head growth that is enhanced by breast milk. This raises the possibility that breast milk may have a modulatory impact on brain growth and development.

This study did not show the calorie intake along with protein, carbohydrate and fat; enteral feed increment and their relation with growth; weekly growth evaluation; specific morbidities and their relation with growth failure. Despite these limitations this study provides information about growth rate of premature infants from birth to 4 weeks of age after comparing with Fenton's growth chart.

\section{Conclusion}

There was decrease in all growth parameters among premature neonate at 4 weeks of life. Despite significant decrease in somatic growth they maintained a near normal head growth. 


\section{References}

1. Mukhopadhyay K, Mahajan R, Louis D, Narang A. Longitudinal growth of very low birth weight neonates during first year of life and risk factors for malnutrition in a developing country. Acta Paediatr 2013;102:278-81.

2. Modi M, Saluja S, Kler N, Batra A, Kaur A, Garg P et al. Growth and Neurodevelopmental Outcome of VLBW Infants at 1 Year Corrected Age. Indian Pediatr 2013;50: 573-467.

3. Velaphi S. Nutritional requirement and parenteral nutrition in preterm infants. S Afr J Clin Nutr 2011; 24: S27-S31.

4. Hack M, Schluchter M, Cartar L, Rahman M, Cuttler L, Borawski E. Growth of very low birth weight infants to age 20 years. Pediatrics. 2003;112:30-38.

5. Ho JJ, Amar HS, Mohan AJ, Hon TH. Neurodevelopmental outcome of very low birth weight babies admitted to a Malaysian nursery. J Pediatr Child Health. 1999;35:175-80.

6. Boo NY, Ong LC, Lye MS, Chandran V, Teoh SL, Zamratol S, et al. Comparison of morbidities in very low birthweight and normal birthweight infants during the first year of life in a developing country. J Paediatr Child Health 1996;32:439-44.

7. Khan NZ, Muslima H, Parveen M, Bhattacharya M, Begum N, Chowdhury S et al. Neurodevelopmental outcomes of preterm infants in Bangladesh. Pediatrics 2006; 118: 280-89.

8. Fenton TR. A new growth chart for preterm babies: Babson and Benda's chart updated with recent data and a new format. BMC Pediatr 2003; 3: 13.

9. Fenton TR, Sauve RS. Using the LMS method to calculate Z-scores for the Fenton preterm infant growth chart. Europian Journal of Clinical Nutrition 2007; 61: 1380-85.

10. Lee ACC, Katz J, Blencowe H, Cousens S, Kojuki N, Vogal JP et al. National and regional estimates of term and preterm babies born small for gestational age in 138 low-income and middle-income countries in 2010. Lancet Glob Health 2013; 1: e26-36.

11. Mackay CA, Ballot DE, Cooper PA. Growth of a cohort of very low birth weight infants in Johannesburg, South Africa. BMC Pediatrics 2011; 11:50-56.

12. Westerberg AC, Henriksen C, Ellingvag A, Veierod MB, Juliusson PB, Nakstad $B$ et al. First year growth among very low birth weight infants. Acta Pediatrica 2010;99:556-62.

13. Knops NB, Sneeuw KC, Brand R, Hille ET, den Ouden AL, Wit JM, VerlooveVanhorick SP: Catch-up growth up to ten years of age in children born very preterm or with very low birth weight.BMC Pediatr 2005, 5:26.

14. Jordan IM, Robert A, Francart J, Sann L, Putet G. Growth in extremely low birth weight infants up to three years. Biol Neonate 2005; 88:57-65.

15. Ehrenkranz RA, Lemons JA, Fanaroff AA, Donovan EF, wright LL, Katsikiotis V et al. Longitudinal growth of hospitalized very low birth weight infants. Pediatrics 1999; 104: 280-89.

16. Cockerill J. Uthaya S, Dore CJ, Modi N. Accelerated postnatal head growth follows preterm birth. Arch Dis Child Fetal Neonatal Ed 2006; 91:F184-F187. 